\title{
loga i educació. Un aprenentatge per a la vida
}

\author{
Dolors Garcia Debesa
}

\author{
Escola Migdia (Girona) \\ dgarci25@xtec.cat
}

Resum: L'escola és un espai per al coneixement d’un mateix i del món, perquè hi podem desenvolupar les qualitats que ens fan realment humans. Aprendre a viure junts, a ser responsables dels nostres actes, a crear un ambient de respecte cap a un mateix $i$ cap als altres, va desenvolupant un codi ètic $i$ social que servirà per conviure en societat. En aquest sentit, el ioga té un text dissenyat per Patanjali (III o II a. de C.) que consta de vuit passos o camins per aconseguir l'estat de ioga (unió). Els dos primers es refereixen al codi dètica i social yama i niyama, paraules en sànscrit que es refereixen a millorar les relacions amb els altres $i \mathrm{amb}$ un mateix.

El ioga contribueix a despertar les intel-ligències múltiples que tenim dins nostre, a ser més creatius, més sensibles, més feliços i més lliures. Per poder fer un bon aprenentatge el cos necessita estar relaxat, la respiració ha de ser lliure, les emocions han d'estar equilibrades i la ment, concentrada: "aprendre a aprendre".

La qualitat de l'educació ha de ser la nostra principal preocupació. Si el projecte educatiu de centre comença per fer persones més humanes, la nostra tasca serà una inversió per a la societat del futur, una societat més culta, més pacifica i més lliure.

Paraules clau: Aprenentatge, educació, unió, benestar, relaxació, atenció, consciència, convivència, afectivitat.
Abstract: School is a place where we develop selfand world-knowledge. It allows us to develop the qualities which make us human, such as learning how to live together, being responsible for our actions and acting respectfully towards oneself and to others. All of this evolves into an ethical and social code that enables us to live together as a society. Similarly, yoga has a text attributed to Patanjali (3rd to 2nd centuries BC) which describes eight steps on the path to reaching a state of yoga (union). The first two steps deal with the social and ethical codes of yama and niyama, Sanskrit terms that refer to ways of improving relations with oneself and with others.

Yoga helps awaken the multiple intelligences that we have within us so that we can become freer, happier, more creative and more sensitive people. To learn effectively, our bodies and breathing need to be relaxed and free, our emotions need to be balanced and the mind must be focused. This is all part of the process of "learning to learn".

Education quality has to be our main concern. If a school's educational ethos is committed to making people more human, it will help lay the foundations for a more cultured and peaceful society in the future.

Keywords: Learning, education, union, health, relaxation, attention, consciousness, coexistence, affection 


\section{Introducció}

La necessitat de donar resposta a alguns interrogants que ens plantegem a vegades com a ensenyants ens fa buscar noves sinergies que vagin en consonància amb el moment actual que vivim. Sabem que l'educació prepara per a la vida i la incorporació a la societat, una societat cada vegada més diversa i plural. Donar a conèixer el ioga als infants, des de petits, és ensenyar-los a utilitzar els seus propis recursos interns perquè puguin fer front a les diverses situacions de la vida quotidiana, amb la finalitat que cada vegada siguin més autònoms i més lliures.

La paraula ioga significa "unió". Es refereix a la unió de la persona en tota la seva globalitat: cos, ment, emocions, espiritualitat. Es tracta de portar a l'educació tot el saber d'aquesta ciència millenària i desenvolupar-lo. Lobjectiu és aconseguir el benestar de l'alumnat i millorar la qualitat de l'ensenyament. En aquest sentit, el treball amb el ioga enllaça amb els quatre pilars de l'educació, quan ens diu que l'educació s'ha d'organitzar al voltant de quatre aprenentatges que seran els pilars del coneixement al llarg de la vida: aprendre a conèixer, aprendre a fer, aprendre a viure junts $i$ aprendre a ser.

A través d'exercicis senzills, els alumnes aprenen a relaxar-se, a concentrar-se, a estimular la seva energia, a prendre consciència del seu cos: "En l'àmbit físic, hi ha postures que activen les cadenes musculars. La seva pràctica afavoreix un bon equilibri que nodreix i estimula els músculs, els tendons i les fàscies, tonifica les articulacions $i$ la columna vertebral" (Garcia, 2011: 50). Aquest despertar corporal és molt beneficiós i s'utilitza a l'aula per millorar el rendiment escolar.

Ens manquen models que ens ajudin a retrobar-nos a nosaltres mateixos. Vivim en una societat en què predomina la sobreestimulació dels sentits externs. El ioga ajuda a fer aquest retrobament i a connectar amb el nostre estat intern.

El treball amb les emocions i els sentiments afavoreix les relacions amb els altres. Si l'alumne està nerviós, crea una barrera per a la circulació de l'energia que es pot convertir en agressivitat. Cal crear un ambient agradable que afavoreixi la convivència. La comunicació és també un factor essencial. Dedicar un temps a parlar, a intercan- viar experiències, a fer preguntes, a verbalitzar les emocions per poder-les reconèixer i acceptar, és el que necessita tota persona per créixer i evolucionar.

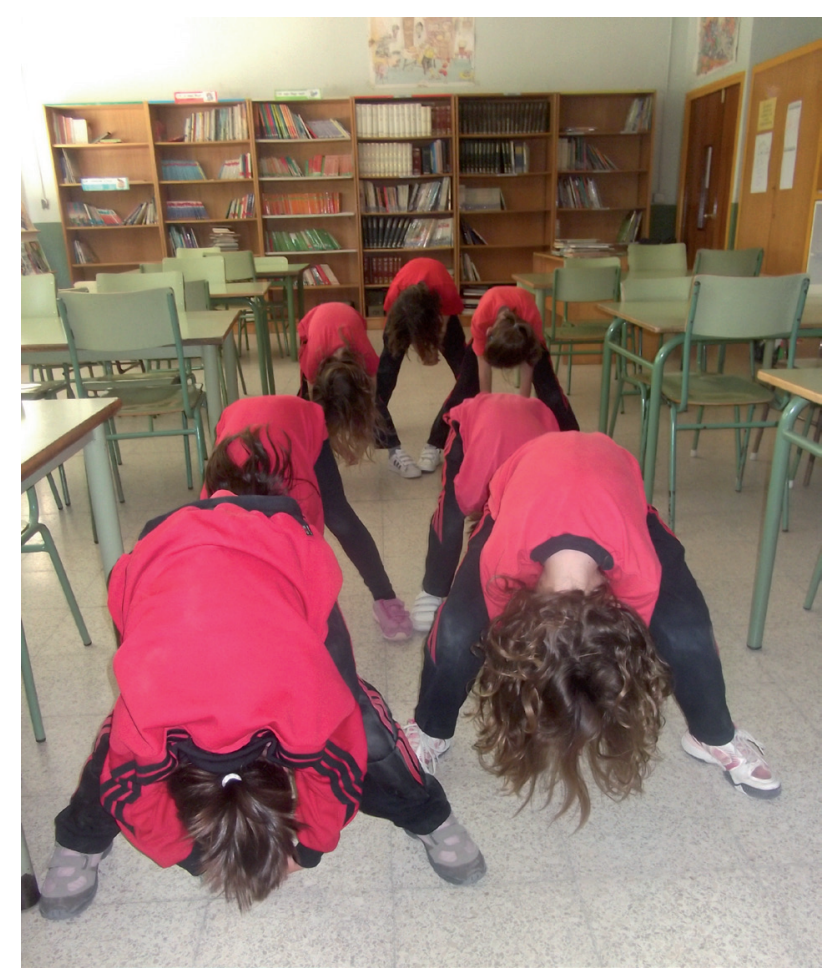

La respiració serveix per conèixer el nostre estat intern i s'utilitza per gestionar les emocions i calmar-les: "La llibertat de moviments del diafragma porta a una millor mobilitat de la pelvis, de la caixa toràcica i dels moviments cranials... D’aquesta manera, la respiració crea un vincle d'equilibri entre la part superior i la part inferior del cos" (Garcia, 2011: 52).

Hi ha diferents tipus de respiracions: tranquillitzants, revitalitzants i equilibrants. La vida accelerada que portem no ens permet estar en contacte amb el ritme de la respiració natural. Recuperar la respiració natural vol dir deixar que es manifesti lliurament. És important connectar-hi i observar-la, i a través d'aquesta observació és quan podrem tenir una experiència directa i entendre-la.

La relaxació, la concentració, la meditació, obren espais interiors més profunds, necessaris a l'aula per anar assimilant els aprenentatges. El neuròleg Nolasc Acarín, en una conferència realitzada el 2003 sobre neuroplasticitat i aprenen- 
tatge, va manifestar: "perquè sigui possible sistematitzar i gravar tot el que s'aprèn, és necessari potenciar el descans a les aules".

La informació que els alumnes reben durant el dia es grava en la massa cerebral gràcies al descans. Si procurem fer petites pauses, permetrem que vagin assimilant tota aquesta informació.

L'escola, després de la família, és el lloc més apropiat per donar a conèixer una sèrie d'aprenentatges i valors que vagin més enllà de les matèries curriculars. El cor i la ment s'han de treballar de forma conjunta. Com diu Krishnamurti (2007: 51), "Només quan el cor i la ment estan integrats hi pot haver intel-ligència i transformació interna. Educar un nen és ajudar-lo a comprendre la llibertat i la integració”.

\section{Ioga. Una experiència a les aules}

A part de la meva experiència personal en l'aplicació del ioga a l'educació, hi ha molts docents al nostre país que estan introduint tècniques de ioga per millorar l'estat dels alumnes i crear un ambient harmònic a l'aula. A través de l'ICE de la $\mathrm{UB}$, hi ha un grup de treball, del qual formo part, que es dedica a compartir experiències i a investigar-ne l'aplicació en diferents àmbits educatius.

Hi ha molts altres països que també n'utilitzen els beneficis. A França, per exemple, el 1973 va entrar al col-legi Condorcet sota el guiatge de Micheline Flak, creadora del RYE a França (Recherche sur le Yoga dans l'Éducation), actualment en seu a l'Hospitalet. El 1988 a Xile van incorporar una alternativa metodològica al pla d'estudis per fer front a l'estrès, la falta de concentració i l'agressivitat, fent servir exercicis de relaxació i respiracions dins l'aula. A l'Uruguai, l'Argentina, els EUA i altres països europeus com Anglaterra, Itàlia, Bèlgica, Alemanya, Holanda o Suïssa també s'utilitza. Estudis realitzats per professionals a Israel i Austràlia donen testimoni que el ioga augmenta les capacitats cognitives dels alumnes.

Vaig tenir l'oportunitat de realitzar el 2007 una llicència d'estudis, concedida pel Departament d'Ensenyament de la Generalitat, que em va permetre donar a conèixer el ioga a un total de quaranta mestres de diferents escoles de primària durant el curs escolar. Això em va permetre aprofundir en el tema i poder valorar els resultats obtinguts.

Les primeres sessions van servir per donar a conèixer el ioga i la seva filosofia. Es pot dir que el ioga és una ciència humanista. Més endavant es va passar a la part pràctica. A través d'exercicis que donava a conèixer als mestres perquè els apliquessin a l'aula, es varen anar treballant $i$ desglossant tots els passos de l'anomenat Astanga Yoga:

1. Treballar junts i millorar les relacions amb l'entorn (yama).

2. Eliminar toxines i pensaments negatius (niyama).

3. Adoptar una postura correcta (asana).

4. Controlar l'energia a través de la respiració (pranayama).

5. Saber-nos relaxar per mantenir la calma i desenvolupar la interiorització (pratyahara).

6. Saber-nos concentrar (dharana).

7. Ampliar la consciència a través de la meditació (dhyana).

En acabar totes les sessions, es va fer una posada en comú amb els mestres participants i van omplir uns qüestionaris que van servir per fer un buidatge dels resultats obtinguts. Aquests resultats van ser molt satisfactoris, ja que els mestres participants van manifestar que volien continuar en el futur aplicant el ioga a les seves classes.

A continuació presentaré alguns dels objectius i exercicis que es van dur a terme.

\section{Objectius Generals}

- Fomentar la cohesió de grup.

- Desenvolupar la consciència corporal.

- Prendre consciència de la respiració.

- Aprendre a relaxar el cos i la ment.

- Desenvolupar l'atenció i la concentració.

\section{Exercicis}

\section{Bon dia}

Al matí, quan arribem a la classe, seiem a la cadira o al terra fent una rotllana.

Comença un alumne i diu bon dia a l'amic que té al seu costat, alhora que expressa una qualitat 
seva. Ex: "Bon dia, Anna. Ets molt maca”, "tens uns ulls molt bonics", "magrada el teu somriure"...).

Beneficis: Treballa l'autoestima i les habilitats socials. Ajuda a crear lligams.

\section{La cigonya}

1. De puntetes, els braços estirats cap enrere, com si fossin dues ales.

2. Porta el pes del cos cap a la cama dreta i estira la cama esquerra enrere. Posa les mans sobre la cama dreta i flexiona el cos endavant tot procurant mantenir l'equilibri.

3. Repeteix l'exercici, canviant de cama, i estira els braços endavant, al costat de les orelles o bé en creu.

Aquesta postura és apropiada a partir de set o vuit anys, ja que en aquesta edat els nens mantenen millor l'equilibri.

Beneficis: Treballa l'equilibri i la concentració. Fa estirar el cos i relaxa la ment.

\section{Cadena de muntanyes}

És una respiració que s'utilitza resseguint el traç amb el dit o mentalment si els alumnes són grans. Inspira tot pujant fins a dalt de la muntanya, exhala tot baixant fins a la plana. Es pot comptar el temps que es tarda per arribar a dalt de la muntanya, però hem de tenir en compte que el de baixada ha de ser el mateix.

Beneficis: Equilibra i harmonitza la respiració, perquè fa que l'aire s'iguali en aquest procés.

\section{Exploració}

1. Sortir al pati i observar amb atenció qualsevol cosa lliurement $\mathrm{i}$ amb tots els sentits. Tornar a l'aula i comentar tot el que els alumnes han observat o percebut. Els més grans poden escriureho a la llibreta.

Beneficis: Afina els sentits i millora la memòria i la capacitat d’atenció i concentració.

\section{Relaxació amb visualització}

Estirats al terra o asseguts a la cadira amb els ulls tancats. Es pot posar una música de fons, tancar el llum o abaixar les persianes i comencem a parlar suaument, convidant al silenci i a l'escolta. És important fer relaxacions en moments que els nens estan molt cansats i necessiten recuperar-se: entrant del pati, al tornar d'una excursió, després d'un examen...

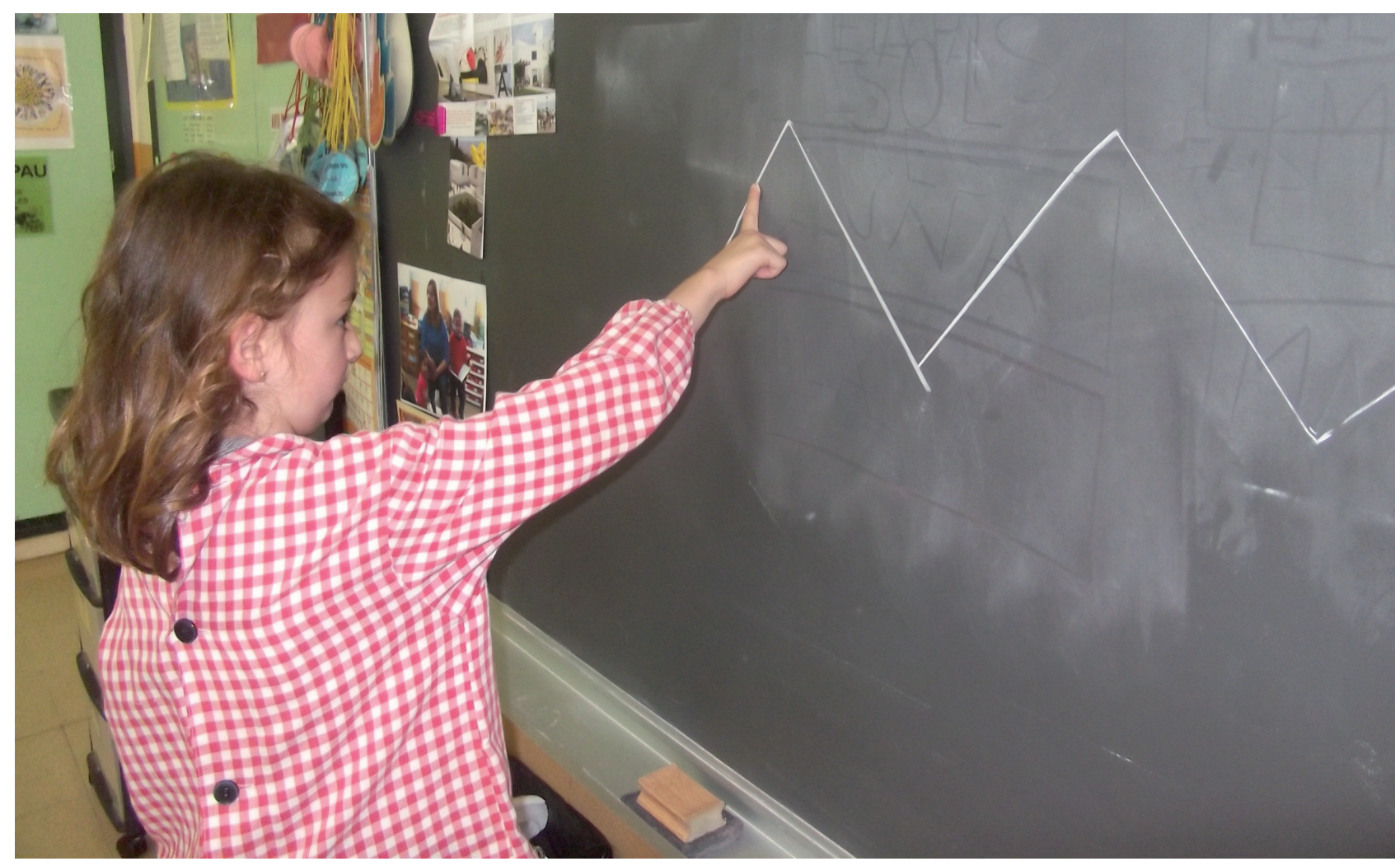




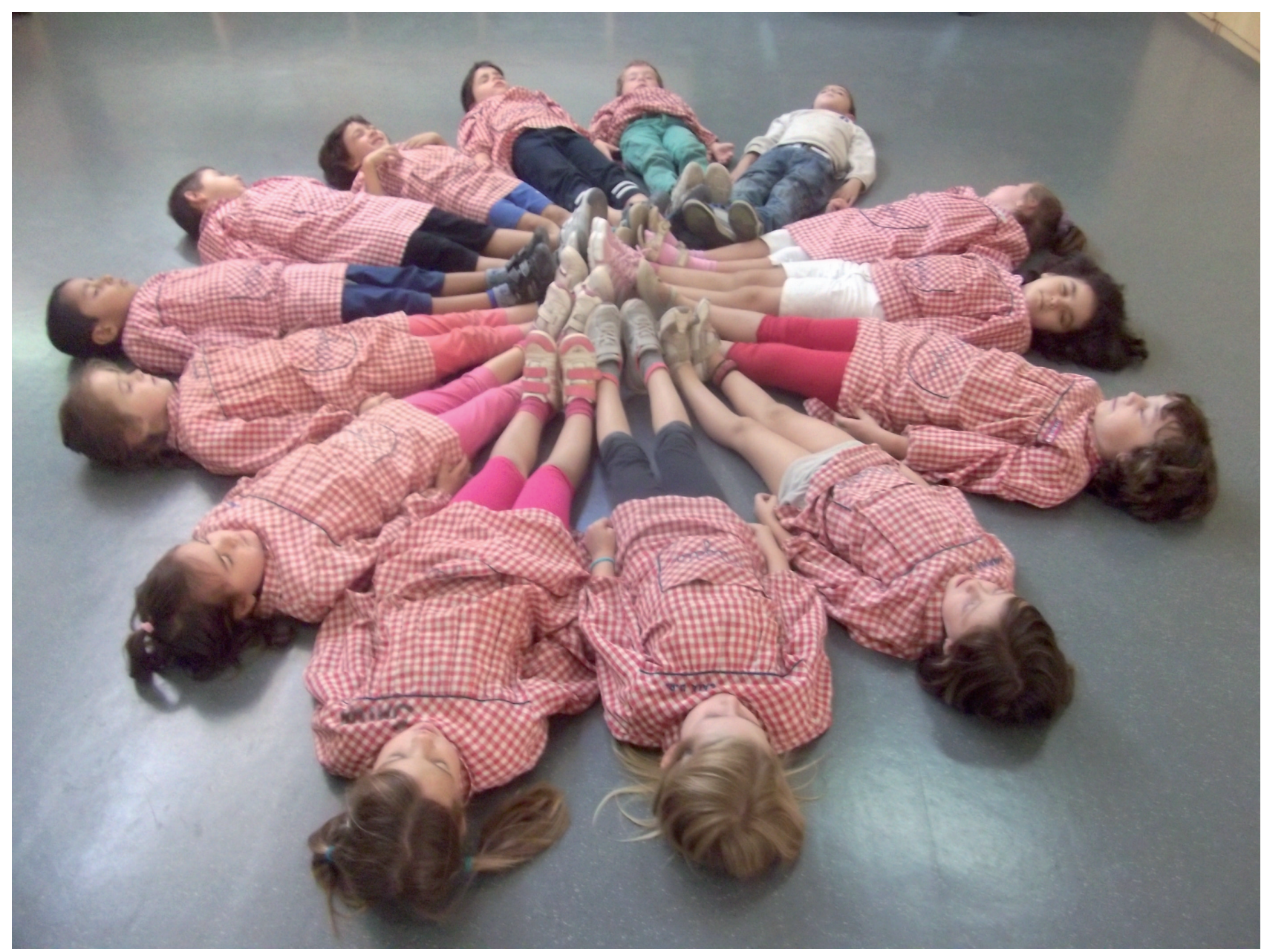

Les visualitzacions són molt interessants perquè ajuden l'alumne a fer volar la seva imaginació. Segons Achterberg (1985), és el procés per mitjà del qual el pensament fa servir els sentits, invocant-los amb alguna finalitat.

Anar relaxant tot el cos: els peus, les cames, l'esquena, el ventre, els braços, la cara... La respiració cada vegada és més tranquil.la, els braços i les mans cada vegada estan més lleugers i relaxats. Nota la seva escalfor... Respira... Relaxa les espatlles, el coll, el cap... Relaxa la cara, el front, els ulls, les galtes, la boca. Tot el teu cos està relaxat i tranquil... A partir d'aquí es comença una visualització guiada, una historia que convidi a la calma (un paisatge, la platja, un jardí...).

En acabar, se surt progressivament de la relaxació. Cal escoltar la respiració i fer-la més profunda, començar a bellugar els dits dels peus i de les mans, moure el cos, estirar-se, fer un badall si ve de gust, i obrir els ulls.

\section{Valoració dels resultats}

Les dades quantitatives del gràfic mostren que un $47 \%$ dels mestres van aplicar alguna activitat de ioga tant al matí com a la tarda, el $43 \%$ ho van fer a la tarda i un $10 \%$ al matí.

A partir de l'anàlisi dels resultats, podem observar com un $42 \%$ dels mestres va valorar de forma molt positiva la incorporació del ioga a l'aula, un $40 \%$ ho va valorar bé i el $18 \%$ força bé. Alguns mestres van comentar la necessitat d'ampliar la seva formació per sentir-se més segurs.

Aquesta resposta em va donar una gran satisfacció, ja que malgrat haver manifestat manca de temps, consideraren molt important una educació integral d'aquests tipus i el 100\% dels mestres van manifestar que continuarien desenvolupant el treball iniciat. 


\section{Conclusions}

La implicació tant dels mestres com dels alumnes envers el projecte i les activitats realitzades em van donar la certesa que és molt important fer un treball global que tingui en compte tots els aspectes de la persona. En aquest sentit, la tasca que vam emprendre junts va ser molt positiva.

L’educació és una tasca per a la vida. La vertadera reforma educativa comença per un mateix. Això implica trobar el temps i l'espai necessaris per reflexionar sobre què volem, quines són les nostres inquietuds, quin és el nostre objectiu i plantejar-nos nous reptes.

S'han d'anar despertant les intel-ligències múltiples que tenim dins i descobrir el nostre potencial. Hem de plantejar-nos quina educació és la que volem i per a què ens ha de servir. No n'hi ha prou amb donar coneixements: s'ha de desenvolupar la intel-ligència, que com ens diu Krishnamurti "és la capacitat de sentir i raonar" (2007: 71). Per tant, la raó ha d'estar integrada amb l'afectivitat: raó i emoció s'han de treballar juntes dins el currículum escolar.
Un clima acollidor dins l'aula dóna seguretat i prepara per a la vida social. El treball amb el ioga serveix per adonar-nos que som iguals i al mateix temps diferents i que hem de caminar junts.

El temps que els alumnes passen a l'escola és una oportunitat per anar fent aquest treball des del respecte, la tolerància, la cooperació i la solidaritat. La qualitat de l'educació ha de ser la nostra principal preocupació si volem que hi hagi una vertadera transformació social.

\section{Bibliografia}

Delors, Jacques (1996). Educació: Hi ha un tresor amagat a dins. UNESCO.

Furlan, E. (1998) Yoga para ninos y niñas. Ed. Hispano Europea.

Flak, M.; De Coulon, J. (2006) Niños que triunfan. Ed. Cuatro Vientos.

Garcia, D. (2011) Ioga i educació. Un aprenentatge per a la vida. Ed. PAMSA.

Hernández, D. (2001) Claves del yoga. Ed. Liebre de Marzo.

LARK, L. (2003) Yoga para niños. Ed. Mens Sana. KrishnamurTi, J. (2007) La educación y el significado de la vida. Ed. Edaf.

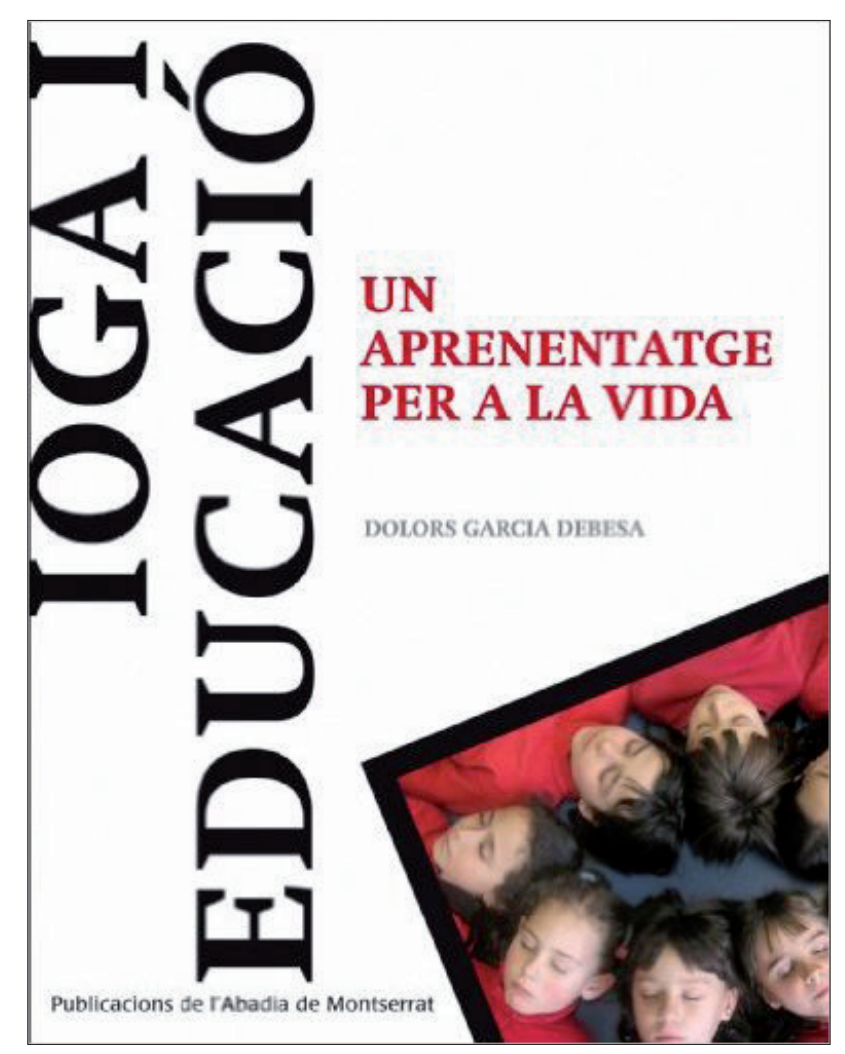

